\title{
Chemically induced anti-predator defences in plankton: a review
}

\author{
Sandra Lass \& Piet Spaak \\ Department of Limnology, EAWAG/ETH, Überlandstrasse 133, CH-8600 Dübendorf, Switzerland \\ Tel: +41 1823 5187. Fax: +41 1823 5315.E-mail lass@eawag.ch
}

Received 5 July 2001; in revised form 29 January 2002; accepted 8 February 2002

Key words: inducible defence, Daphnia, ciliate, rotifer, algae, kairomone, adaptation, cost, identification

\begin{abstract}
Planktonic organisms exhibit diverse morphological, behavioural and life-history responses to the chemical presence of potential predators. Prey organisms have been found to sense such predators via predator-derived kairomones. The induced reactions are assumed to reduce predation risk and thus to be adaptive. Numerous studies have investigated various aspects of inducible defences in different crustaceans, in rotifers, planktonic ciliates and algae. As a first step, we summarise recent work on chemically induced anti-predator defences in morphology, life history and behaviour. Morphological defences have been found in a wide range of different plankton organisms and recent studies on predator-induced morphologies mainly addressed the question of costs for these changes. Life-history responses were mainly studied in cladocerans and several studies have recently addressed some novel topics, such as diapause induction and the influence of predator kairomones on hatching of resting stages. Behavioural anti-predator defences also have been found for several plankton species and are characterised by relatively fast induction times. We further identified four research directions in which substantial progress has been made recently: (I) The effects of simultaneous exposure to infochemicals from different predators and the consequences of a complex chemical environment. Some environmental contaminants, such as synthetic chemicals or heavy metals, have been found to potentially disturb natural chemical communication in aquatic predator-prey systems. (II) The influence of genetic variation on the reaction to infochemicals and its implications. Clonal differences have not only been found for the presence or absence of a certain trait but also with respect to the type of response. (III) The degree to which different types of responses to a specific kairomone are coupled. Recent studies underline the uncoupling of different anti-predator responses of which some have been considered to be coupled. (IV) Studies on the chemical properties and on the metabolic origin of predator kairomones. Substantial progress has been made recently, especially with respect to the identification of predator kairomones that are important for planktonic ciliates. The identification and isolation of kairomones are an important step towards studies addressing the consequences of predator-induced defences on the level of populations, communities and ecosystems. So far most studies have considered effects and consequences on the level of individual prey organisms and studies taking the consequences at higher ecological levels into account are rare.
\end{abstract}

\section{Introduction}

Predator-induced responses in plankton have elicited increasing research interest within the last two decades. Since Larsson \& Dodson (1993) reviewed the state-of-the-art of the research on chemical communication in planktonic animals, further studies on this phenomenon have been carried out and several new research lines on anti-predator defences in plankton have developed.
Chemical communication is a well-known ecological phenomenon mediating interactions between organisms via infochemicals (Dicke \& Sabelis, 1992). Kairomones constitute the class of infochemicals evoking a behavioural or physiological reaction in the receiver that is adaptively favourable for the receiver but not for the sender. Predator-derived kairomones play an important role in ecological and evolutionary processes that enable the prey to survive predation pressure. The wide variety of responses to predator 
chemical cues and the diversity of taxa which are responsive to predator kairomones in terrestrial, freshwater and marine habitats has been reviewed recently (Kats \& Dill, 1998). Furthermore, the factors favouring the evolution of inducible defences have been presented by Tollrian \& Harvell (1999) in a book spanning a wide organismal range.

In aquatic ecosystems, planktonic organisms are able to detect the presence of potential predators through kairomones (Krueger \& Dodson, 1981; Hebert \& Grewe, 1985; Dodson, 1988; Dodson, 1989; de Meester, 1993; Loose et al., 1993; Tollrian, 1994). This enables planktonic organisms to exhibit predator-specific responses that reduce predation risk. It is especially interesting to study predator-induced responses for planktonic prey, since there is little possibility of seeking a physical refuge from predators in the open water zone. It is known that behavioural, morphological and life-history changes in planktonic prey can offer refuge from predation. Chemically induced anti-predator defences have been found in a wide range of different planktonic organisms among which are algae, ciliates, rotifers, insect larvae, and several planktonic crustaceans (see reviews by Havel, 1987; Larsson \& Dodson, 1993; Wicklow, 1997; Snell, 1998).

Cladocerans of the genus Daphnia, rotifers, ciliates and algae, as a consequence of their asexual reproduction, their ecological relevance, their fast life cycles and the ease of cultivation, have become model organisms for investigations of the ecological relevance and the evolutionary consequences of kairomoneinduced changes. Chemical-induced responses have been found to be a widespread, ecologically and evolutionary important phenomenon in these groups. Rotifers, namely Brachionus calyciflorus, have been the first planktonic organisms, for which reactions to predator kairomones derived from the predatory rotifer Asplanchna were found (de Beauchamp, 1952a, b; Gilbert, 1966). Rotifer predators include notonectids, copepods, cladocerans and predatory rotifers (e.g. Stemberger \& Gilbert, 1984; Marinone \& Zaragese, 1991). In 1985, inducible morphological changes were described for ciliates of the genus Euplotes that were exposed to kairomones from ciliate predators of the genus Lembadion (Kuhlmann \& Heckmann, 1985). Euplotes also have many different predators among freshwater ciliates, amoebans and turbellarians that all induce morphological anti-predator reactions.

Most predators feed size-selectively and different predators differ in their predation strategies. Plankti- vorous fish hunt visually and prefer larger Daphnia prey, whereas larvae of the phantom midge Chaoborus are tactile hunters and preferably feed on smaller Daphnia. Amoeban predators are not restricted to a certain size of their Euplotes prey, whereas ciliates like Lembadion and turbellarians such as Stenostomum are restricted due to the size of their pharynxes (Kusch, 1993a). As a consequence, different predators represent different selective forces and kairomones from different predators evoke predator-specific reactions (Brett, 1992; Kusch, 1993a; Stibor \& Lüning, 1994). Predation is an important evolutionary force (Lynch, 1980; Stemberger \& Gilbert, 1984; Kuhlmann \& Heckmann, 1985; Kerfoot \& Sih, 1987; Stibor, 1992; Kusch, 1993a; Lürling \& van Donk, 1997; Wicklow, 1997; Rengefors et al., 1998) and predator kairomones have been shown to shape morphology (e.g. Hessen \& van Donk, 1993; Kusch, 1993b; Tollrian, 1994), life history (e.g. Washburn et al., 1988; Macháček, 1991; Weider \& Pijanowska, 1993; de Meester \& Weider, 1999) and behaviour (e.g. Dodson, 1989; Neill, 1990; de Meester, 1993; Kusch, 1993a; Kuhlmann, 1994; Pijanowska, 1994; Kleiven et al., 1996; von Elert \& Loose, 1996; de Meester \& Cousyn, 1997; Pijanowska \& Kowalczewski, 1997a; Gilbert \& Hampton, 2001).

In contrast to freshwater plankton, there are few investigations on the role of predator infochemicals in marine plankton (e.g. Strand \& Hamner, 1990; Bollens et al., 1994; Cieri \& Stearns, 1999; Hamren \& Hansson, 1999). Some studies have shown that marine copepods react to mechanical or visual stimuli, rather than to chemicals exuded by predatory fish (Bollens \& Frost, 1989a; Bollens et al., 1994) and several marine plankton species use bioluminescence for communication. However, two recent studies have demonstrated that marine planktonic crustaceans (copepods, mysidaceans) reduce feeding activity in the presence of fish kairomones (Cieri \& Stearns, 1999; Hamren \& Hansson, 1999). The resulting reduction in gut fullness has been proposed to be adaptive in reducing visibility to predators (Bollens \& Stearns, 1992), which has been shown for other planktonic organisms (Giguère \& Northcote, 1987). These studies indicate that predator kairomones might also play an important role for anti-predator defences in marine plankton. However, chemical ecology of predator-induced defences in marine plankton is in its infancy and further research is necessary to compare the role of predator kairomones in marine and freshwater ecosystems.

Since the review of Larsson \& Dodson (1993) some lines of research on the effects of kairomones on 
Table 1. Investigations on morphological, life-history and behavioural responses of planktonic organisms to predator kairomones published after Larsson \& Dodson's review (1993)

\begin{tabular}{|c|c|c|}
\hline Morphology & Life history & Behaviour \\
\hline Costs for the prey & Diapause induction & Alertness \\
\hline (Barry, 1994) & (Slusarczyk, 1995) & (Kuhlmann, 1994) \\
\hline (Kusch \& Kuhlmann, 1994) & (Pijanowska \& Stolpe, 1996) & (de Meester \& Pijanowska, 1996) \\
\hline (Lüning, 1994) & (Boersma et al., 1998) & (Boersma et al., 1998) \\
\hline (Repka et al., 1994) & (Ślusarczyk, 1999) & (Brewer et al., 1999) \\
\hline (Lüning, 1995b) & (Ślusarczyk, 2001) & Swarming \\
\hline (Tollrian, 1995b) & Dormancy & (Pijanowska, 1994) \\
\hline (Repka \& Pihlajamaa, 1996) & (Hansson, 1996) & (Pijanowska \& Kowalczewski, 1997b) \\
\hline (Spaak \& Boersma, 1997) & (Blaustein, 1997) & (Jensen et al., 1998) \\
\hline (Scheiner \& Berrigan, 1998) & (Rengefors et al., 1998) & Diel Vertical Migration \\
\hline (Caramujo \& Boavida, 2000) & Diverse & (Young \& Watt, 1993) \\
\hline Adaptive value & (Macháček, 1993) & (Ringelberg \& Flik, 1994) \\
\hline (Kuhlmann \& Heckmann, 1994) & (Weider \& Pijanowska, 1993) & (de Meester et al., 1995) \\
\hline (Kusch, 1995) & (Lüning, 1994) & (McKelvey \& Forward Jr., 1995) \\
\hline (Lüning, 1995a) & (Stibor \& Lüning, 1994) & (Ringelberg \& van Gool, 1995) \\
\hline (Stibor, 1995) & (Macháček, 1995) & (Stirling, 1995) \\
\hline (Repka et al., 1995) & (Reede, 1995) & (Ringelberg et al., 1997) \\
\hline (Tollrian, 1995a) & (Reede, 1997a) & (Horppila, 1997) \\
\hline (Dodson \& Wagner, 1996) & (Pijanowska \& Kowalczewski, 1997a) & (Boriss \& Gabriel, 1998) \\
\hline (Wicklow, 1997) & (Pijanowska, 1997) & (Gilbert \& Hampton, 2001) \\
\hline (Fyda \& Wiackowski, 1998) & (Scheiner \& Berrigan, 1998) & Phototaxis \\
\hline (Agrawal et al., 1999) & (Boersma et al., 1999) & (de Meester \& Cousyn, 1997) \\
\hline Consequences for predators \& populations & (Burks et al., 2000) & (van Gool \& Ringelberg, 1995) \\
\hline (Kusch, 1998) & (Stibor \& Navarra, 2000) & (van Gool \& Ringelberg, 1997) \\
\hline Diverse & (Mikulski, 2001) & (van Gool \& Ringelberg, 1998b) \\
\hline (Tollrian, 1993) & & (van Gool \& Ringelberg, 1998a) \\
\hline (Chapman \& Burns, 1994) & & Swimming behaviour \\
\hline (Tollrian, 1994) & & (Dodson et al., 1997a) \\
\hline (Lysebo, 1995) & & (Dodson et al., 1997b) \\
\hline \multirow[t]{9}{*}{ (Brancelj et al., 1996) } & & (Dodson et al., 1995) \\
\hline & & Horizontal migration \\
\hline & & (Watt \& Young, 1994) \\
\hline & & (Kvam \& Kleiven, 1995) \\
\hline & & (Kleiven et al., 1996) \\
\hline & & (Lauridsen \& Lodge, 1996) \\
\hline & & (O’Bryan \& Forrester, 1997) \\
\hline & & (Burks et al., 2001b) \\
\hline & & (Burks et al., 2001a) \\
\hline
\end{tabular}

planktonic organisms have received increasing interest (I) Inducible defences in a complex chemical environment, especially the effects of a simultaneous exposure to infochemicals from multiple predators differing in their foraging strategies, (II) the genetic variation in the reaction to infochemicals and its implications, (III) the question to what degree different types of responses to a specific kairomone are coupled, and (IV) the properties of the mediating predator kairomones. In this review, we concentrate on those new research lines but we also review progress that has been made in research lines already described by Larsson \& Dodson (1993) (Table 1).

We stress that the choice of the presented four new lines reflects our opinion of their importance, which we gained while reviewing the literature in this 
field. Furthermore, it is important to mention that Daphnia will be taken as the general model organism and will be extensively discussed but wherever other planktonic model systems lead to interesting or even contrasting results we will mention and discuss them. We will show that several questions are similar although the planktonic predator-prey model systems might differ.

\section{Recent progress and developments on established research themes}

\section{Morphological reactions to predator kairomones}

Morphological anti-predator reactions are widespread in planktonic organisms and have been found in algae (e.g. Hessen \& van Donk, 1993; Lampert et al., 1994; Lürling \& van Donk, 1997; Lürling, 1998, 1999a; Lürling \& Beekman, 1999; Lürling \& van Donk, 2000), ciliates (for review see Wicklow, 1997), rotifers (de Beauchamp, 1952a,b; Gilbert, 1966; Marinone \& Zaragese, 1991) and crustaceans (for review see Tollrian \& Dodson, 1999). Research on predator-induced morphological changes has especially addressed the costs and benefits of morphological anti-predator changes for prey organisms.

Generally, inducible defences are believed to cause costs that are saved in the absence of predators; otherwise constitutive defences would have been favoured by natural selection (Harvell, 1990). For Daphnia, researchers had great difficulties to show the expected physiological costs of neckteeth formation (Tollrian \& Dodson, 1999). The costs reported by some authors have been shown to be trade-offs of life-history reactions to Chaoborus kairomones, leading to the conclusion that no direct costs result from neckteeth formation for Daphnia (Tollrian, 1995b; Repka \& Pihlajamaa, 1996). In contrast, morphological defences in ciliates have been found to cause metabolic costs. In Euplotes, proteinsynthesis is necessary for predatorinduced changes in morphology (Kusch \& Kuhlmann, 1994). These metabolic costs cause increased generation times (Kuhlmann, 1992). Thus population growth rate was reduced and anti-predator morphological changes therefore cause demographic costs (Kusch \& Kuhlmann, 1994). Similar demographic costs of anti-predator morphologies were found in rotifers. At high food concentrations, the predator-induced morph of the rotifer Keratella testudo has less than half of the intrinsic rate of population increase than the noninduced morph (Stemberger, 1988). Furthermore, the extent of morphological defence has been observed to correlate with the prevailing predation risk in ciliates (Kusch, 1993a, 1995). The observed adjustment of morphological changes to the actual predation risk indicates that costs are involved and that these are saved under reduced or in the absence of predation risk. In planktonic algae, no direct metabolic costs could be found for being colonial (Lürling \& van Donk, 2000) but Lürling \& van Donk (2000) state that costs might be attributed to enhanced sinking of coenobia out of the euphotic zone. Such environmental costs, i.e. interactions of inducible defences with the environment, might also exist for neckteeth in Daphnia (Jacobs, 1967; Tollrian \& Dodson, 1999) and have been proposed for vertical migration behaviour (Dawidowicz \& Loose, 1992; Loose \& Dawidowicz, 1994) and for horizonzal migration (Burks et al., 2001b). Tollrian \& Dodson (1999) state that costs may have been studied in a simplified context. Phenotypic changes and inducible defences might impose various other costs and limits than simply metabolic costs (Agrawal \& Karban, 1998; DeWitt et al., 1998). One limit may be that adaptations to one predator regime might be unfavourable in the presence of other predators. As morphological changes generally increase visibility they might be disadvantageous in the presence of visually hunting predators (Tollrian, 1995b). Furthermore, selection should favour effective defences at low or no costs and thus costs might be absent or small and difficult to measure, but still relevant for prey populations (Tollrian, 1995b; Tollrian \& Dodson, 1999).

Some studies on morphological defences have focussed on the question of the adaptive value of these traits. Since morphological defences mostly include the development of protuberant forms and thus an increase in body size, they are especially common and effective as a response to predators that are sizelimited to small prey (Kusch, 1993a). Especially in predation experiments with induced and non-induced ciliates (Kuhlmann \& Heckmann, 1985, 1994; Kusch, 1995; Wicklow, 1997; Fyda \& Wiackowski, 1998) and rotifers (Stemberger \& Gilbert, 1984), induced morphological changes have proven to be effective anti-predator strategies and to increase prey survival considerably. Thus, these defences allow the coexistence of predator and prey, which has been confirmed in population experiments (Kusch, 1993a; Wicklow, 1997; Kusch, 1998). An Euplotes species that did not exhibit anti-predator defences went extinct in the presence of its Amoeba predator whereas a defended species was able to coexist with the same predator 
(Kusch, 1993a). Also for cladocerans (Repka et al., 1994; Repka et al., 1995; Tollrian, 1995a; Dodson \& Wagner, 1996; Repka \& Pihlajamaa, 1996), the adaptive value of morphological defences has been demonstrated. Tollrian (1995a) and Dodson \& Wagner (1996) have shown that neckteeth in Daphnia increase survivorship in the presence of Chaoborus. In contrast, Lüning (1995a) showed that D. pulex that were previously exposed to Chaoborus kairomone were less susceptible to Chaoborus predation, regardless of whether or not they had neckteeth. Lüning (1995a) suggests that the increased survivorship after pre-exposure to the predator kairomone might not only result from morphological defences but also from predator-avoidance behaviour. Furthermore, crested Daphnia have been shown to be less susceptible to Notonecta predation than conspecifics without crests (Grant \& Bayly, 1981). And fish predators have problems ingesting spined D. lumholtzi and prefer nonspined prey (Barnhisel, 1991; Swaffar \& O’Brien, 1996). Stibor (1995) has shown that Daphnia that were previously exposed to fish kairomone had increased survival chances; unfortunately his study does not allow to determine the exact reason for this increased survivorship.

Most investigations on chemically induced defences have focussed on the costs and benefits for the prey and have neglected the impact on the predator. Research on morphological anti-predator responses has recently started to investigate the consequences of inducible defences for the predator and for whole plankton communities (Wicklow, 1997; Kusch, 1998). Kusch (1998) investigated population growth rates of predators and defended prey over several generations in laboratory experiment and also developed a mathematical model describing population growth. His results indicate that population growth of predators is greatly diminished in the presence of defended prey if no alternative undefended prey is available. The author concludes that under natural conditions, where several prey species may co-exist, predators might not suffer considerably from inducible defences in prey (Kusch, 1998). However, if selection pressure due to prey defence is strong for predators, they are expected to become capable of responding phenotypically to induced prey defences. This has been observed for the ciliate Onychodromus indicus that is able to transform into six morphometrically distinct phenotypes in response to the type of available prey (Kamra \& Sapra, 1994).

\section{Life-history reactions to predator kairomones}

One of the most extreme life-history changes in response to predator kairomones has been observed in ciliates (Washburn et al., 1988). Larvae of the treehole mosquito, Aedes sierrensis, release kairomones that induce the free-living prey Lambornella clarki (Ciliophora: Tetrahymenidae) to form parasitic cells that infect and kill their mosquito predators. Most work on predator-induced life-history changes in plankton has been conducted on cladocerans (Table 1) and has recently addressed some novel topics. Changes in lifehistory traits have been observed in different Daphnia species as reactions to kairomones exuded by invertebrate (Weider \& Pijanowska, 1993; Stibor \& Lüning, 1994; Weber \& Declerck, 1997) as well as by vertebrate predators (Weider \& Pijanowska, 1993; Stibor \& Lüning, 1994; Macháček, 1995; Reede, 1995, 1997a; Reede \& Ringelberg, 1998; de Meester \& Weider, 1999; Mikulski, 2001). By adapting resource allocation to growth and reproduction the impact of predation can be reduced and the chance of zooplankton reproducing successfully before being eaten is increased. One recent study pinpoints the costs of lifehistory adaptations by showing that offspring of mothers reacting to fish kairomones are more susceptible to starvation (Stibor \& Navarra, 2000).

Diapause has been proposed as a predator avoidance strategy (Hairston, 1987). Recently, diapause induction has also been found to be one of the lifehistory traits in Daphnia which may potentially be induced by predator kairomones (Ślusarczyk, 1995; Pijanowska \& Stolpe, 1996; Ślusarczyk, 1999, 2001). This ability introduces a new dimension to antipredator responses in plankton, since it would enable Daphnia to avoid the predator in time instead of facing the enemy through defences. Pijanowska \& Stolpe (1996) suggested that under heavy predation pressure, with a low chance of survival for parthenogenetic females, resting egg formation may result in a higher fitness than immediate reproduction. D. magna has been shown to produce resting eggs as a reaction to the chemical presence of fish in combination with specific environmental conditions such as a long day photoperiod, high temperature and moderate food concentrations (Ślusarczyk, 1995; Pijanowska \& Stolpe, 1996; Ślusarczyk, 1999, 2001). It is important to mention that evidence for this reaction norm so far has been documented in a single $D$. magna clone. Therefore, up to now it is not justified to consider kairomone-induced diapause as a general 
phenomenon in Daphnia. Resting egg production as a response to predation was also postulated by other authors, but could neither be demonstrated in a study on 16 D. magna clones (Boersma et al., 1998) nor in a mesocosm experiment with 20 clones from the $D$. galeata species complex (Spaak \& Boersma, 2001).

Furthermore, planktonic resting stages have been proposed to delay and reduce hatching in the presence of predator kairomones (Hansson, 1996; Blaustein, 1997; Rengefors et al., 1998). Hansson (1996) observed a significantly reduced recruitment rate of flagellated algae species from the sediment in the presence of caged alive or dead Daphnia thus implying that this is a chemically induced response to predator presence. In laboratory experiments, Rengefors et al. (1998) have shown that dinoflagellate excystment was reduced in the presence of zooplankton exudates. Results of a mesocosm study on crustaceans suggest that resting eggs of three copepod and cladoceran species also might be able to detect Salamander kairomones and to respond with delayed hatching (Blaustein, 1997). However, these first results need to be confirmed in further experiments by exposing crustacean resting eggs to predator kairomones.

\section{Behavioural reactions to predator kairomones}

In contrast to predator-induced life-history responses and morphological changes, which can be established within one generation (Stibor, 1992), behavioural traits give Daphnia the possibility of reacting to predatory danger within hours. Recent studies demonstrate that $D$. magna may exhibit a fully induced change in phototactic behaviour after a few hours of exposure to fish kairomones (de Meester \& Cousyn, 1997). An almost immediate sensitisation in the presence of fish kairomones has been shown for a D. galeata $\times$ hyalina hybrid (Ringelberg \& van Gool, 1995). Since the phototactic reactions in Daphnia are the underlying mechanism for diel vertical migration (DVM), these results led to the conclusion that DVM can also be induced rapidly. Neill (1990) found a rapid initiation $(<4 \mathrm{~h})$ of vertical migration in previously non-migrating freshwater copepods as a response to Chaoborus introduction. Furthermore, it is likely that other behavioural responses (e.g. alertness, swarming, horizontal migration) have comparably short induction times. Rapidly inducible predator-avoidance behaviour has also been observed in the ciliate Euplotes as a response to kairomones from Amoeba predators which are not strictly size-selective (Kusch, 1993a).
Most recent work on predator-induced defences in Daphnia completely or partially deals with behavioural traits (Table 1). Changes in phototactic behaviour, aggregation behaviour and escape abilities also can be induced by damaged conspecifics and have been proven to be effective predator avoidance strategies (Pijanowska \& Kowalczewski, 1997b). In contrast to other studies, Stirling (1995) even has found that $D$. galeata mendotae did not exhibit antipredator behaviour in response to fish kairomone alone but reacted only to chemical cues from fish that had fed on Daphnia. These results indicate that for some prey species or clones alarm signals from conspecifics may be relevant for the induction of anti-predator defences. Some of the predator-induced changes in Daphnia behaviour (e.g. DVM) have been known by aquatic biologists for some time (see Bayly, 1986), whereas others were described more recently (e.g. escape behaviour, 'alertness'). 'Alertness' is defined as the capability to escape the attack of a predator through an increased sensitivity to mechanical and light disturbance (de Meester \& Pijanowska, 1996). D. magna clones that had been incubated in fish water exhibited a more pronounced alertness compared to control animals which were not exposed to predator kairomones (de Meester \& Pijanowska, 1996). These results were confirmed by Brewer (1999) who observed an increase in swimming speed (as a measure of alertness) in Daphnia in the presence of fish. Escape responses have been described for the ciliate Euplotes that was pre-exposed to kairomones from its turbellarian predator Stenostomum (Kuhlmann, 1994). However, this behaviour needed a second stimulus in addition to kairomones and was only exhibited after physical contact with the predator.

One meaning of aggregation and swarming is most likely the reduction of predation risk for individual prey. Visually orientating predators like fish might be confused by the enormous number of potential prey organisms in a swarm (Heller \& Milinski, 1979) resulting in a reduced predator efficiency. Laboratory experiments have demonstrated that patchiness of Daphnia tends to increase in the presence of fish or fish kairomones (Pijanowska, 1994; Pijanowska \& Kowalczewski, 1997b; Jensen et al., 1998). Laboratory experiments with Antarctic krill, Euphausia superba, have demonstrated a reaction to excretory material from vertebrate predators by changing their schooling behaviour and causing the school to disperse (Strand \& Hamner, 1990). This indicates that schooling could also be disadvantageous for planktonic organisms in 
the presence of predators; krill swarms may be easier to detect by predators especially by seabirds from the air than individual krill organisms. However, Strand \& Hamner (1990) hypothesise that the reactions of krill to nitrogenous endproducts could as well be an avoidance mechanism to high ammonia levels produced by the swarm itself rather than an anti-predator defence. They stress the need for further testing of these ideas.

Most attention and research on predator-induced behaviour in Daphnia has been focussed on diel vertical migration (DVM) behaviour as a strategy to reduce predation risk (Lampert, 1987; Ringelberg \& Flik, 1994; de Meester, 1995; Ringelberg \& van Gool, 1995). This behavioural trait offers an escape from predation in space since the prey avoids water layers of high predation risk. The proximate cause for this behaviour is a phototactic reaction to relative changes in light intensity (Ringelberg, 1987, 1999), whereas the reduction of predation pressure due to visually hunting predators like fish is considered to be the most important ultimate reason for DVM (Zaret \& Suffern, 1976; Lampert, 1993). Although Daphnia also show phototactic responses in the absence of fish exudate (Ringelberg, 1993), there is experimental evidence that fish infochemicals enhance this phototactic reaction (Ringelberg, 1991). While relative changes in light intensity trigger this behaviour and determine the direction for the up- and downward movement, the presence of fish and their kairomones seems to determine the period in the course of the year during which migration occurs in the field (Ringelberg et al., 1991b). It has been shown that zooplankton only shows typical migrations when their predominant predators are present (Bollens \& Frost, 1989b; Ringelberg et al., 1991b; Bollens et al., 1992). Based on these observations, Ringelberg (1997) formulated the hypothesis that the migration amplitude depends on the biomass of fish in a lake. This hypothesis is underlined by laboratory experiments, in which daytime depth of Daphnia correlated positively with fish density (Loose, 1993). A recent study shows that the extent by which lake water enhanced the phototactic reaction of Daphnia in a biotest was indeed positively correlated to the biomass of juvenile fish in that lake (van Gool \& Ringelberg, 1999).

In contrast to the regular migration pattern, with an ascent at dusk and a descent at dawn, the presence of invertebrate predators, exhibiting a regular DVM themselves, can induce reverse migration in Daphnia, rotifers, and marine and freshwater copepods (Ohman et al., 1983; Bayly, 1986; Neill, 1990;
Horppila, 1997; Gilbert \& Hampton, 2001). By staying deep during darkness, zooplankton can reduce its predation risk due to tactile invertebrate predators feeding near the surface at night. In contrast to these results, McKelvey \& Forward (1995) found that the exposure of Artemia franciscana to chemical cues from non-visually hunting chaetognaths which exhibit DVM themselves did not induce a phototactic ascent response which is the underlying mechanism for a reverse vertical migration.

In addition to DVM, several plankton species have been reported to migrate horizontally (Taleb et al., 1993; Watt \& Young, 1994; Kvam \& Kleiven, 1995; Lauridsen et al., 1996; O’Bryan \& Forrester, 1997; Lauridsen et al., 1998; Lauridsen et al., 1999; Burks et al., 2000) and several patterns of horizontal migration have been observed (e.g. seasonal, daily) (O'Bryan \& Forrester, 1997). Diel horizontal migration is especially important in shallow lakes that lack a hypolimnetic refuge and in which DVM thus is not an effective predator avoidance strategy. Burks et al. (2001b) found substantial predation pressure of littoral benthic macroinvertebrates on horizontally migrating Daphnia and conclude that the adaptive value of diel horizontal migrations might differ among lakes. Some invertebrate predators exploit the fact that their prey organisms swim at right angles to the plane of polarization of the ambient light by themselves swimming parallel to the plane of polarization (Young \& Taylor, 1990). Kleiven (1996) found that D. pulex swims away from a source of Chaoborus incubation water. These observations were supported in a field study recording dense swarms of D. longispina (up to 4000 animals $\mathrm{L}^{-1}$ ) along the littoral zone in a lake where Chaoborus flavicans is considered the main predator (Kvam \& Kleiven, 1995).

\section{New research lines}

\section{Inducible defences in a complex chemical environment}

The simultaneous exposure of prey to predators with different feeding strategies and different prey selectivity is of special interest since different kinds of predators may co-occur in nature (Sih et al., 1998). Due to the different selective pressures, Daphnia and ciliates have been shown to react with different traits, depending on the hunting tactics and the size-selectivity of the relevant predator. The importance of a multiple 
predator environment and potentially conflicting prey defences has been increasingly recognised recently (Sih et al., 1998). Although not reported for plankton, other aquatic animals have been shown to react differently when simultaneously exposed to two different chemical stimuli (Petranka, 1989). Toad tadpoles left areas containing alarm signals from injured conspecifics, but exhibited only partial avoidance of areas containing both alarm and food signals, thus balancing their behaviour to conflicting chemical signals. However, research into this area is constrained because the chemical composition of several kairomones is not known and because it is hardly possible to offer the substances in equal or relevant concentrations.

Additional complications in achieving definitive results in this field arise due to variations in the relative importance of different predators in a given lake and because predators may not co-occur in time. High densities of both planktivorous fish and Chaoborus, for example, will not be found simultaneously in one lake (Weber \& Declerck, 1997). Weber \& Declerck (1997) refer to the relative importance of different predators in a lake as a possible explanation for their observation that the effects induced by the Chaoborus kairomone are neutralised by fish kairomone in a mixed treatment. According to the hypothesis of local adaptation it is expected that zooplankton will react strongly to the dominating predator, while showing a weak or no response to rare predators. The relative importance of certain predators within one habitat can also change with time (Stibor \& Lampert, 2000). Stibor \& Lampert (2000) found that the size at first reproduction of the $D$. hyalina population in a mesotrophic lake was reduced in summer when fish predation was high whereas it was increased in autumn when Chaoborus larvae were abundant. Furthermore, they found a change in reproductive allocation in response to fish kairomone, but not to Chaoborus kairomone. These observations indicate that one of two co-existing predators can be more important for the prey than the other which is an important selective force for the prey populations in these habitats and selects for those clones that are better adapted to the dominating predator.

The interference of anthropogenic chemical substances with predator kairomones in aquatic ecosystems and the effects of synthetic substances on predator-prey interactions have received increasing attention in recent years (Hanazato, 1992; Hanazato \& Dodson, 1992, 1993; Hanazato, 1995; Barry, 1998; Barry, 1999; Michels et al., 1999; Preston et al., 1999a; Preston et al., 1999b; Michels et al., 2000; Dang Kieu et al., 2001). Anthropogenic substances can mimic the effects of predator kairomones or inhibit the induction of defences and have therefore the potential to disturb natural chemical signalling in predator-prey systems (Barry, 1999; Hanazato, 1999). Some synthetic chemicals, such as insecticides and pesticides, and heavy metals have been found to induce protuberant morphologies similar to those induced by invertebrate kairomones (Hanazato \& Dodson, 1993; Barry, 1998). The rotifer Brachionus calyciflorus increases its swimming speed in the presence of pentachlorophenol (PCP), whereas a reduction in swimming speed is found as an anti-predator reaction in the presence of Asplanchna predators (Preston et al., 1999a). When both, PCP and Asplanchna were present, this behaviour led to increased predation. Thus, responses of planktonic organisms to environmental contaminants potentially affect predator-prey interactions and may result in fatal consequences for plankton communities. The direct effects of these chemicals on organisms, their interactions with natural cues and their indirect effects on plankton communities are potentially interesting not only for ecotoxicologists, but also for ecological and evolutionary questions. Unravelling the mechanisms of how anthropogenic chemicals with a known chemical structure disturb chemical signalling might also improve the understanding of the functioning of natural communication systems.

\section{Interclonal differences in reaction to kairomones}

Larsson \& Dodson (1993) already reported that there is genetic variation for the type and amplitude of predator-induced reactions. So, this research line is not completely new. There are a few early investigations of clonal differences in anti-predator reactions addressing questions of local adaptation (Parejko \& Dodson, 1991), or of costs of inducible defences (Spitze, 1992). However, since 1993 genetic differences in the response to kairomones have received increasing research attention. While the first studies on predator-induced reactions were done with single Daphnia clones and single species, recent studies compare several clones and taxa and provide evidence that not the mean value of a specific trait, but its variance is of major ecological and evolutionary importance for natural zooplankton populations (de Meester, 1990; Parejko \& Dodson, 1991; Watt \& Young, 1992; Weider \& Pijanowska, 1993; Young \& 
Watt, 1994; de Meester \& Pijanowska, 1996; Reede, 1997a; Weber \& Declerck, 1997; Boersma et al., 1998; Boersma et al., 1999; Weber, 1999). Boersma et al. (1998) showed that clonal differences are not only found for the presence or absence of a response. Moreover, clonal differences are also observed with respect to the type of response shown (the trait with which the animal responds). Lürling (1999a) also reported considerable variation in anti-grazer responses of different strains of the green algae Scenedesmus to Daphnia kairomones. For a comprehensive review on genetic differentiation within zooplankton see de Meester (1996b).

Some studies on genetic differences have further explored the idea of local adaptation to habitat-specific predation regimes. Clones from habitats with fish proved to be more responsive to fish kairomones than clones from fishless locations (de Meester, 1996a; Boersma et al., 1999). These results indicate that there is a relationship between the specific response of a clone and predator-mediated chemicals and its evolutionary history with respect to the presence of the particular predator in the habitat from which the clone is derived (Parejko \& Dodson, 1991; de Meester, 1996a; Boersma et al., 1998; Boersma et al., 1999).

In addition to differences in predation regimes among habitats there might as well be differences within a habitat. These differences can be either spatial (e.g. between different microhabitats such as between epi- and hypolimnion) or temporal (e.g. when the type or the intensity of predation). Some studies have investigated whether migrating and nonmigrating Daphnia from the same habitat differ in their life-history strategies (Stich \& Lampert, 1984; Reede \& Ringelberg, 1995; Reede, 1997b; Reede \& Ringelberg, 1998). Reede \& Ringelberg (1995; 1998) showed that non-migrating $D$. hyalina $\times$ galeata clones exhibit stronger life-history reactions to fish kairomones than migrating clones. de Meester \& Weider (1999) found that Daphnia clones inhabiting the epilimnion during the day were generally smaller, both in the absence and in the presence of fish kairomones, than clones isolated from the hypolimnion. The results of these studies imply a co-adaptation of habitat selection and size-related life-history traits. Cousyn et al. (2001) investigated the consequences of rapid temporal changes in fish community structure for the plankton community in a fishpond. The authors hatched Daphnia resting eggs derived from different sediment depths that correlated with periods of different fish densities in the pond. Clones from periods with high predation pressure exhibited a stronger behavioural response to fish kairomones than clones from periods of lower fish density (Cousyn et al., 2001). These results lead to the conclusion that predation can cause rapid evolutionary changes in prey communities and that changes in predation intensity leads to temporal changes in local adaptation.

Several studies on clonal differences have shown that the clonal composition of Daphnia populations in one habitat can change with the season (Hebert, 1974a, b; Wolf, 1987; Spaak, 1996). Some authors found evidence for temporal habitat selection in Daphnia populations, with clones isolated in different seasons exhibiting typical life-history characteristics. In a recent study, life-history reactions to fish and Chaoborus kairomones by six clonal cohorts isolated in monthly intervals from a mesotrophic lake were studied and compared with life-history characteristics of animals from this lake (Stibor \& Lampert, 2000). A reduced size at first reproduction (SFR) was only found in summer when fish predation was high, whereas Chaoborus kairomone increased SFR exclusively in times when Chaoborus larvae were abundant in the lake. Stibor \& Lampert (2000) concluded that this indicates a seasonal shift in the clonal composition of $D$. hyalina populations towards clones that are adapted to the prevailing predation regime. Unfortunately, the authors did not confirm this with molecular analyses of the clonal structure.

\section{The uncoupling of responses - are the different reactions to predator kairomones coupled?}

All the responses discussed so far have been separately interpreted as adaptive mechanisms to avoid or counterbalance predation risk, and it has been assumed implicitly that Daphnia should react with as many different traits as possible. However, de Meester \& Pijanowska (1996) argued that it may not be adaptive to exhibit all responses simultaneously. If single traits are effective anti-predator defences, there is no need to exhibit additional responses. It has been observed that there is an association between DVM and lifehistory traits with large-bodied genotypes remaining at greater depths (de Meester, 1994; de Meester et al., 1995). Although DVM and a smaller body size both reduce fish predation risk, the combination of both anti-predator defences might be disadvantageous. For example, it is not advantageous to reduce body size at times of vertical migration because food is generally less abundant at greater depths, and large Daphnia can 
better cope with low food levels than small ones. A selection experiment (de Meester et al., 1995) with three differently sized $D$. galeata $\times$ hyalina clones has shown that different combinations of DVM behaviour and life histories may result in similar relative fitness values.

There is evidence for the uncoupling of different anti-predator responses. Boersma et al. (1998) demonstrated that $16 \mathrm{D}$. magna clones exhibited completely different combinations of reactions for 12 independent anti-predator traits. All clones showed a significant reaction to fish kairomones for at least one trait, but no clone responded with all traits under study. Some investigations on the coupling of multiple responses to predator kairomones were carried out to test the assumption that inducible defences are related to costs and that therefore different reactions might be coupled (Lüning, 1994; Tollrian, 1995b; Repka \& Pihlajamaa, 1996). It was further assumed that the costs of inducible defences can be measured as a reduction in fitness (Black \& Dodson, 1990). Some of these studies demonstrate that an exposure of Daphnia to Chaoborus cues results in the production of neckteeth, but also in a larger size at maturity, a late maturation and a reduced reproductive output (e.g. Stibor \& Lüning, 1994; Lüning, 1995a), whereas others show that neckteeth induction and life-history changes do not always co-occur (Spitze, 1992; Black, 1993; Lüning, 1994). Weber \& Declerck (1997) observed an increased growth rate of Daphnia in the presence of Chaoborus kairomone, but in contrast to earlier studies (Stibor \& Lüning, 1994), no reduction in reproductive output. Although this lack of lifehistory changes has been interpreted as evidence for low costs of neckteeth formation (Black, 1993), it is more likely that these results give further evidence for the uncoupling of different adaptive responses. It is important to differentiate between constraints and adaptive responses. Boersma et al. (1998) conclude that life-history changes are adaptive responses in their own right, rather than the result of constraints imposed by the development of other defences.

\section{Chemical characterisation of infochemicals}

Given the fact that the role of kairomones for plankton was already observed about half a century ago (de Beauchamp, 1952a, b) and has been intensively studied since then, knowledge about the chemical structure of the mediating infochemicals in freshwater ecosystems is still scarce. The first attempt to describe the chemical characteristics of a predator kairomone playing a role in plankton was made by Gilbert (1967) for the Asplanchna factor. So far, predator kairomones inducing anti-predator defences in ciliates have been identified (Kusch \& Heckmann, 1992; Kusch, 1993a, c), and the so-called Lembadion-factor (derived from the predatory ciliate Lembadion) is the only predator kairomone for which origin and primary structure are known (Peters-Regehr et al., 1997). The isolation and identification of predator kairomones is of great interest since their identification would contribute insight into a number of ecological and evolutionary questions (e.g. Snell, 1998).

Knowledge of the chemical nature and the origin of a kairomone facilitates measurements of effective and natural concentrations (Peters-Regehr et al., 1997). Furthermore, it allows detection of the meaning of this chemical for the predator. There has been controversy discussion about why organisms invest in producing infochemicals that mediate interactions, which are unfavourable for the sender. It has been argued that a chemical that is detrimental to the sending organism, such as predator kairomones, should be selected against. Nordlund \& Lewis (1976) stated that the evolutionary persistence of a kairomone depends on the overall benefit the sender gains from this substance. The defence-inducing Amoeba kairomone has, for example, been found to be a self-recognition signal that prevents cannibalism in Amoeba and thus increases its survival (Kusch, 1999). Thus, this function seems to outbalance the negative effect of anti-predator defences in their prey.

It has become evident that Daphnia and ciliates can differentiate between kairomones from different predators and respond with different anti-predator defences (e.g. Stibor \& Lüning, 1994; Wicklow, 1997). The ciliate Euplotes octocarinatus develops morphological defences against Lembadion (Kuhlmann \& Heckmann, 1985), and exhibits behavioural and morphological anti-predator reactions to Stenostomum (Kusch, 1993b; Kuhlmann, 1994) and Amoeba predators (Kusch, 1993a). The Lembadion kairomone is a protein with a size of $31500 \mathrm{Da}$ (Kusch \& Heckmann, 1992), whereas the Stenostomum kairomones is a protein with a size of 17500 Da (Kusch, 1993c). Hence, kairomones are predator-specific. For Daphnia, it is not clear if they are able to distinguish between different predator species, such as different fish species or if they can differentiate between planktivorous versus non-planktivorous fishes. Such ability would be advantageous since not all fish species feed on Daphnia. 
In some studies, all kinds of fishes, even benthic, nonplanktivorous species, have been shown to evoke a behavioural reaction in Daphnia, suggesting that the effective kairomone is an unspecific chemical (Loose et al., 1993; von Elert \& Loose, 1996). Similar results exist for the fish-Artemia model system (Forward Jr \& Rittschof, 1993; McKelvey \& Forward $\mathrm{Jr}$, 1995). In contrast, results of a recent laboratory study (Weber, 1999) suggest that different fish species (perch and stickleback) affect Daphnia life histories differently, indicating that Daphnia is able to differentiate between fishes. However, the interpretation of these results remains difficult until the fish kairomone is identified; and it is not known whether these differences may merely reflect concentration-dependent differences in the response to the predator kairomone.

Results of laboratory experiments with Daphnia and fish kairomones suggest that it is not fish per se, but fish-associated microorganisms that are involved in the production of kairomones. Perch treated with an antibiotic induced a weaker phototactic reaction in Daphnia than untreated perch, implying that it is not fish but bacteria associated with fish that produce the fish kairomone (Ringelberg \& van Gool, 1998). This was also suggested for the relevant kairomone in the brine shrimp (Artemia)-fish model system (Forward Jr $\&$ Rittschof, 1999). Since bacteria are generally not fish species specific, these observations would explain why several fish species evoke a similar response in Daphnia.

Although the chemical structures of the relevant kairomones for Daphnia are still unknown, some progress has been made with their characterisation (Lampert et al., 1994; Tollrian \& von Elert, 1994; von Elert \& Loose, 1996; von Elert \& Pohnert, 2000) (Table 2). In all cases, the kairomones are water-soluble and non-volatile. In contrast to the cues that are relevant for ciliates (Kusch \& Heckmann, 1992; Kusch, 1993c), the kairomones from fish and Chaoborus have been found to have a low molecular weight and do not seem to be proteins (Loose et al., 1993; Tollrian \& von Elert, 1994). A recent study showed that the substance trimethylamine (TMA), which is present in marine and freshwater fish, induces vertical displacement reactions in Daphnia (Boriss et al., 1999). These findings have initiated a controversy not only about the ecological relevance of this substance, but also about the concentrations which were tested (von Elert \& Pohnert, 2000). Studies testing the effect on Daphnia life histories have shown that TMA does not induce the same reactions as fish kairomones
(Sakwińska, 2000; Lass et al., 2001). Furthermore, von Elert \& Pohnert (2000) have shown that TMA is volatile and looses its effect after evaporation, whereas fish incubation water remains effective after evaporation. Further studies (Pohnert \& von Elert, 2000; Hendry \& Burns, 2001) have demonstrated that TMA is present in fish incubation water at concentrations several orders of magnitude lower as determined in the initial study of Boriss et al. (1999). Pohnert and von Elert (2000) further show that such low concentrations are not sufficient to induce phototactic behaviour in Daphnia. The results of these studies indicate that TMA cannot be a substantial component of the fish kairomone.

For the fish-Artemia system, McKelvey \& Forward (1995) found a similar phototactic reaction by brine shrimp to fish kairomone and to the odour from a non-migrating, non-visually hunting ctenophore predator. The authors suggest that the fish cue may be part of the external mucus and that the unexpected similarity of the reaction to both predators may be explained as a response to chemicals common to mucus (McKelvey \& Forward Jr, 1995). If so, then the reaction of brine shrimp to general compounds of mucus from different predators would not be consistent with the findings that anti-predator responses are predator-specific and adaptive. Forward \& Rittschof (1999) tested whether enzymatic degradation products of polysaccharides, which can occur in fish mucus, induce photoresponses in brine shrimp. The tested substances evoked phototactic behaviour similar to the reaction induced by fish mucus in Artemia franciscana and were furthermore found in fish incubation water. Whether these polysaccharide-derivatives also play a role in the fish-Daphnia system remains to be studied. It should be mentioned that some of the characteristics of these chemicals are not consistent with findings of von Elert \& Loose (1996).

For the Daphnia-Scenedesmus system, urea has been found to be an excretory nitrogen product of Daphnia and to induce colony formation in the green algae under certain conditions (Wiltshire \& Lampert, 1999). In contrast, other studies (Lampert et al., 1994; Lürling, 1999b) reported no effect of urea on colony formation which shows that the role of urea in mediating anti-grazer responses in Scenedesmus is not fully understood.

Since the mediating predator kairomones are not known, bioassays are used to quantify the amount of kairomones in aquatic ecosystems (Loose, 1993; Loose et al., 1993; Tollrian \& von Elert, 1994; Stir- 
Table 2. Key papers that characterise the four new research lines in chemically induced anti-predator defences in plankton defined in the text

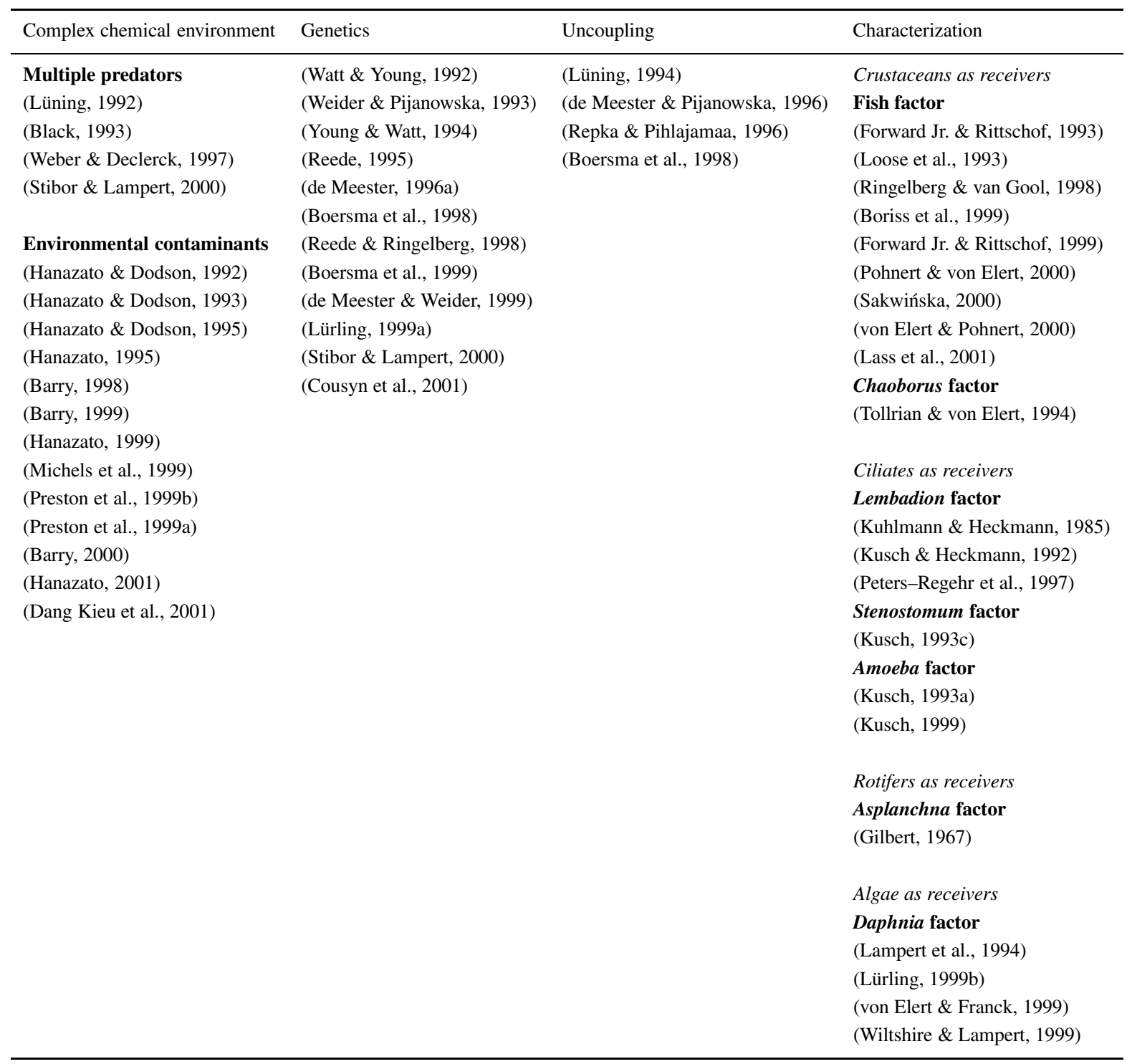

ling, 1995; van Gool \& Ringelberg, 1995). Since the reactions of the prey to kairomones are very specific, bioassays are also useful for further characterisation of the relevant infochemicals (Forward Jr \& Rittschof, 1993; Tollrian \& von Elert, 1994; Ringelberg \& van Gool, 1998; Boriss et al., 1999; Lürling, 1999b). Biotests are needed to detect the effective fraction of a kairomone that has been fractionated with biochemical methods (von Elert \& Loose, 1996). The combination of a good biotest and chemical fraction- ing techniques will be the only way to elucidate the chemical composition of kairomones (Snell, 1998).

\section{Synopsis and perspectives for future research}

During the last decades, there has been an increasing research interest in predator-induced defences in plankton. Studies, mainly on ciliates, have shown that morphological, life-history and behavioural re- 
sponses indeed reduce predation risk and increase the prey's fitness in the presence of potential predators. These results indicate that predator kairomones affect predator efficiency and are therefore certain to influence the trophic structure of an ecosystem. It has been hypothesised that kairomones and inducible defences have a regulating function on the flow of matter within a food web (Ringelberg et al., 1991a; Ringelberg, 1997). Matsuda et al. (1994) state that predator-specific defence affects community structure and allows a much more complex community and a larger niche overlap between predators than non-specific defence. Furthermore, inducible responses have been suggested to influence dominance and succession patterns in algae communities (Hansson, 2000). Experimental and modelling results indicate that inducible defences may intensify fluctuations of prey populations since population growth rate is less regulated by a defence-inducing predator than by a non-inducing predator (Kusch, 1998). Kusch's results further suggest predator population growth to be greatly diminished when exclusively defended prey is present. Marinone \& Zagarese (1991) conducted mesocosm experiments with plankton communities and found an indirect effect of fish presence on morphological changes in rotifers. In the presence of planktivorous fish reducing crustacean abundance, Keratella tropica reduced caudal spines most probably as a reaction to reduced predation risk (Marinone \& Zaragese, 1991). All these studies intent to show consequences of chemical-induced anti-predator defences for communities. However, few studies made this attempt so far and there is definitely need for increased research effort.

Most investigations on predator-induced defences and their impact on the prey's fitness are laboratory experiments which have been done with single or a few predator and prey species, and not with whole plankton communities. The results of laboratory experiments on a few prey and predator species do not explain what predator-induced responses actually mean for the prey's fitness in natural environments and for the structure of the whole pelagic food web. Although predation experiments with induced and noninduced prey and studies on the simultaneous exposure to kairomones from different predators are a step into the direction of studying food web interactions, these investigations are limited due to the fact that kairomone concentrations cannot be measured and the results are difficult to be interpreted. The interpretation of field results also remains restricted unless the chemical nature of the relevant predator kairomones is known and concentrations can be determined. Therefore, direct knowledge on the ecological relevance and evolutionary consequences of predator-induced defences in plankton communities is scarce. In order to determine the impact of kairomone-mediated changes on food web structure and function, it is necessary to combine results of laboratory studies with those of field investigations, such as Stibor \& Lampert (2000) did in their recent study. In conclusion, progress on a better understanding of the ecological importance of chemical communication in predator-prey systems will benefit substantially from the characterisation of the chemical structure of infochemicals and from the synthesis of laboratory and field results.

\section{Acknowledgements}

We thank Luc de Meester, Maarten Boersma, Prof. J.V. Ward and five anonymous reviewers for stimulating comments on earlier versions of this manuscript. This research was supported by a grant from the Swiss Federal Office for Education and Science (no. 97.0040) which is linked to the contract ENV4CT97-0402 within the framework of the European Commission's Environment and Climate Programme that is part of the project network WatER (Wetland and Aquatic Ecosystem Research). This support is gratefully acknowledged.

\section{References}

Agrawal, A. A. \& R. Karban, 1998. Why induced defenses may be favored over constitutive strategies in plants. In Harvell, C. D. \& R. Tollrian (eds), Ecology and Evolution of Inducible Defenses. Princeton University Press, Princeton, USA: 45-61.

Agrawal, A. A., C. Laforsch \& R. Tollrian, 1999. Transgenerational induction of defences in animals and plants. Nature 401: 60-63.

Barnhisel, D. R., 1991. Zooplankton spine induces aversion in small fish predators. Oecologia 88: 444-450.

Barry, M. J., 1994. The costs of crest induction for Daphnia carinata. Oecologia 97: 278-288.

Barry, M. J., 1998. Endosulfan-enhanced crest induction in Daphnia longicephala: evidence for cholinergic innervation of kairomone receptors. J. Plankton Res. 20: 1219-1231.

Barry, M. J., 1999. Chemical communication in planktonic organisms: environmental contaminants can mimic the effects of natural chemical signals. SETAC Europe News 10: 6-8.

Barry, M. J., 2000. Effects of endosulfan on Chaoborus-induced life-history shifts and morphological defenses in Daphnia pulex. J. Plankton Res. 22: 1705-1718.

Bayly, I. A. E., 1986. Aspects of diel vertical migration in zooplankton, and its enigma variations. In de Deckker, P. \& W. D. 
Williams (eds), Limnology in Australia. Dr W. Junk Publishers, Dordrecht, The Netherlands: 349-368.

Black, A. R., 1993. Predator-induced phenotypic plasticity in Daphnia pulex: life history and morphological responses to Notonecta and Chaoborus. Limnol. Oceanogr. 38: 986-996.

Black, A. R. \& S. I. Dodson, 1990. Demographic costs of Chaoborus-induced phenotypic plasticity in Daphnia pulex. Oecologia 83: 117-122.

Blaustein, L., 1997. Non-consumptive effects of larval Salamandra on crustacean prey: can eggs detect predators? Oecologia 110: 212-217.

Boersma, M., L. de Meester \& P. Spaak, 1999. Environmental stress and local adaptation in Daphnia magna. Limnol. Oceanogr. 44: 393-402.

Boersma, M., P. Spaak \& L. de Meester, 1998. Predator-mediated plasticity in morphology, life history, and behavior of Daphnia: the uncoupling of responses. Am. Nat. 152: 237-248.

Bollens, S. M. \& B. W. Frost, 1989a. Predator-induced diel vertical migration in a planktonic copepod. J. Plankton Res. 11: 10471065.

Bollens, S. M. \& B. W. Frost, 1989b. Zooplanktivorous fish and variable diel vertical migration in the marine planktonic copepod Calanus pacificus. Limnol. Oceanogr. 34: 1072-1083.

Bollens, S. M., B. W. Frost \& J. R. Cordell, 1994. Chemical, mechanical and visual cues in the vertical migration behavior of the marine planktonic copepod Acartia hudsonica. J. Plankton Res. 16: $555-564$

Bollens, S. M., B. W. Frost, D. S. Thoreson \& S. J. Watts, 1992. Diel vertical migration in zooplankton - field evidence in support of the predator avoidance hypothesis. Hydrobiologia 234: 33-39.

Bollens, S. M. \& D. E. Stearns, 1992. Predator-induced changes in the diel feeding cycle of a planktonic copepod. J. Exp. Mar. Biol. Ecol. 156: 179-186.

Boriss, H., M. Boersma \& K. H. Wiltshire, 1999. Trimethylamine induces migration of waterfleas. Nature (398): 382 . Boriss, H. \& W. Gabriel, 1998. Vertical migration in Daphnia: the role of phenotypic plasticity in the migration pattern for competing clones or species. Oikos 83: 129-138.

Brancelj, A., T. Celhar \& M. Sisko, 1996. Four different head shapes in Daphnia hyalina (Leydig) induced by the presence of larvae of Chaoborus flavicans (Meigen). Hydrobiologia 339: 37-45.

Brett, M. T., 1992. Chaoborus and fish-mediated influences on Daphnia longispina population structure, dynamics and life history strategies. Oecologia 89: 69-77.

Brewer, M. C., P. Dawidowicz \& S. I. Dodson, 1999. Interactive effects of fish kairomone and light on Daphnia escape behavior. J. Plankton Res. 21: 1317-1335.

Burks, R. L., E. Jeppesen \& D. M. Lodge, 2000. Macrophyte and fish chemicals suppress Daphnia growth and alter life-history traits. Oikos 88: 139-147.

Burks, R. L., E. Jeppesen \& D. M. Lodge, 2001a. Littoral zone structures as Daphnia refugia against fish predators. Limnol. Oceanogr. 46: 230-237.

Burks, R. L., E. Jeppesen \& D. M. Lodge, 2001b. Pelagic prey and benthic predators: impact of odonate predation on Daphnia. J. N. am. Benthol. Soc. 20: 615-628.

Caramujo, M. J. \& M. J. Boavida, 2000. Induction and costs of tail spine elongation in Daphnia hyalina $\times$ galeata: reduction of susceptibility to copepod predation. Freshwat. Biol. 45: 413423.

Chapman, M. A. \& C. W. Burns, 1994. Polymorphism and food limitation in three Daphnia carinata populations. Int. Rev. ges. Hydrobiol. 79: 477-509.
Cieri, M. D. \& D. E. Stearns, 1999. Reduction of grazing activity of two estuarine copepods in response to the exudate of a visual predator. Mar. Ecol. Progr. Ser. 177: 157-163.

Cousyn, C., L. de Meester, J. K. Colbourne, L. Brendonck, D. Verschuren \& F. Volckaert, 2001. Rapid local adaptation of zooplankton behavior to changes in predation pressure in absence of neutral genetic changes. Proc. Natl. Acad. Sci. U.S.A. 98: 6256-6260.

Dang Kieu, N., E. Michels \& L. de Meester, 2001. Phototactic behavior of Daphnia and the continuous monitoring of water quality: interference of fish kairomones and food quality. Environ. Toxicol. Chem. 20: 1098-1103.

Dawidowicz, P. \& C. J. Loose, 1992. Metabolic costs during predator-induced diel vertical migration of Daphnia. Limnol. Oceanogr. 37: 1589-1595.

de Beauchamp, P., 1952a. Un facteur de la variabilité chez les rotifrès du genre Brachionus. Comptes rend. Acad. Sci. 234 573-575.

de Beauchamp, P., 1952b. Variation chez les rotifrès du genre Brachionus. Comptes rend. Acad. Sci. 235: 1355-1356.

de Meester, L., 1990. Evidence for intra-population genetic variability for phototactic behaviour in Daphnia magna Straus, 1820. Biol. Jb. Dodonaea 58: 84-93.

de Meester, L., 1993. Genotype, fish-mediated chemicals, and phototactic behavior in Daphnia magna. Ecology 74: 1467-1474.

de Meester, L., 1994. Life histories and habitat selection in Daphnia: divergent life histories of $D$. magna clones differing in phototactic behaviour. Oecologia 97: 333-341.

de Meester, L., 1995. Life history characteristics of Daphnia magna clones differing in phototactic behaviour. Hydrobiologia 307: $167-175$.

de Meester, L., 1996a. Evolutionary potential and local genetic differentiation in a phenotypically plastic trait of a cyclical parthenogen, Daphnia magna. Evolution 50: 1293-1298.

de Meester, L., 1996b. Local genetic differentiation and adaptation in freshwater zooplankton populations: patterns and processes. Ecoscience 3: 385-399.

de Meester, L. \& C. Cousyn, 1997. The change in phototactic behaviour of a Daphnia magna clone in the presence of fish kairomones: the effect of exposure time. Hydrobiologia 360: 169-175.

de Meester, L. \& J. Pijanowska, 1996. On the trait-specificity of the response of Daphnia genotypes to the chemical presence of a predator. In Lenz, P. H., D. K. Hartline, J. E. Purcell \& D. L. Macmillan (eds), Zooplankton: Sensory Ecology and Physiology. Gordon and Breach, Amsterdam, The Netherlands: 407-417.

de Meester, L. \& L. J. Weider, 1999. Depth selection behavior, fish kairomones, and the life histories of Daphnia hyalina $\times$ galeata hybrid clones. Limnol. Oceanogr. 44: 1248-1258.

de Meester, L., L. J. Weider \& R. Tollrian, 1995. Alternative anti-predator defences and genetic polymorphism in a pelagic predator-prey system. Nature 378: 483-485.

DeWitt, T. J., A. Sih \& D. S. Wilson, 1998. Costs and limits of phenotypic plasticity. Trends Ecol. Evol. 13: 77-81.

Dicke, M. \& M. W. Sabelis, 1992. Costs and benefits of chemical information conveyance: proximate and ultimate factors. In Roitberg, B. D. \& M. B. Isman (eds), Insect Chemical Ecology: An Evolutionary Approach. Chapman and Hall, New York, U.S.A.: 122-155.

Dodson, S. I., 1988. The ecological role of chemical stimuli for the zooplankton: predator-avoidance bahavior in Daphnia. Limnol. Oceanogr. 33: 1431-1439. 
Dodson, S. I., 1989. The ecological role of chemical stimuli for the zooplankton: predator-induced morphology in Daphnia. Oecologia 78: 361-367.

Dodson, S. I., T. Hanazato \& P. R. Gorski, 1995. Behavioral responses of Daphnia pulex exposed to carbaryl and Chaoborus kairomone. Environ. Toxicol. Chem. 14: 43-50.

Dodson, S. I., S. Ryan, R. Tollrian \& W. Lampert, 1997a. Individual swimming behavior of Daphnia: effects of food, light and container size in four clones. J. Plankton Res. 19: 1537-1552.

Dodson, S. I., R. Tollrian \& W. Lampert, 1997b. Daphnia swimming behavior during vertical migration. J. Plankton Res. 19: 969-978.

Dodson, S. I. \& A. E. Wagner, 1996. Temperature affects selectivity of Chaoborus larvae-eating Daphnia. Hydrobiologia 325: 157161.

Forward Jr, R. B. \& D. Rittschof, 1993. Activation of photoresponses of brine shrimp nauplii involved in diel vertical migration by chemical cues from fish. J. Plankton Res. 15: 693-701.

Forward Jr, R. B. \& D. Rittschof, 1999. Brine shrimp larval photoresponses involved in diel vertical migration: Activation by fish mucus and modified amino sugars. Limnol. Oceanogr. 44: 1904-1916.

Fyda, J. \& K. Wiackowski, 1998. Benefits and costs of predatorinduced morphological changes in the ciliate Colpidium kleini. Euro. J. Protistol. 34: 118-123.

Giguère, L. A. \& T. G. Northcote, 1987. Ingested prey increase risks of visual predation in transparent Chaoborus larvae. Oecologia 73: 48-52.

Gilbert, J. J., 1966. Rotifer ecology and embryological induction. Science 151: 1234-1237.

Gilbert, J. J., 1967. Asplanchna and postero-lateral spine production in Brachionus calyciflorus. Arch. Hydrobiol. 64: 1-62.

Gilbert, J. J. \& S. E. Hampton, 2001. Diel vertical migrations of zooplankton in a shallow, fishless pond: a possible avoidanceresponse cascade by notonectids. Freshwat. Biol. 46: 611-621.

Grant, J. W. G. \& I. A. E. Bayly, 1981. Predator induction of crests in morphs of the Daphnia carinata King complex. Limnol. Oceanogr. 26: 201-218.

Hairston, N. G., 1987. Diapause as a predator avoidance adaptation. In Kerfoot, W. C. \& A. Sih (eds), Predation: Direct and Indirect Impacts on Aquatic Communities. University Press of New England, Hanover, U.S.A.: 281-290.

Hamren, U. \& S. Hansson, 1999. A mysid shrimp (Mysis mixta) is able to detect the odour of its predator (Clupea harengus). Ophelia 51: 187-191.

Hanazato, T., 1992. Insecticide inducing helmet development in Daphnia ambigua. Arch. Hydrobiol. 123: 451-457.

Hanazato, T., 1995. Combined effect of the insecticide carbaryl and the Chaoborus kairomone on helmet development in Daphnia ambigua. Hydrobiologia 310: 95-100.

Hanazato, T., 1999. Anthropogenic chemicals (insecticides) disturb natural organic chemical communication in the plankton community. Environ. Pollut. 105: 137-142.

Hanazato, T., 2001. Pesticide effects on freshwater zooplankton: an ecological perspective. Environ. Pollut. 112: 1-10.

Hanazato, T. \& S. I. Dodson, 1992. Complex effects of a kairomone of Chaoborus and an insecticide on Daphnia pulex. J. Plankton Res. 14: 1743-1755.

Hanazato, T. \& S. I. Dodson, 1993. Morphological responses of four species of cyclomorphic Daphnia to a short-term exposure to the insecticide carbaryl. J. Plankton Res. 15: 1087-1095.

Hanazato, T. \& S. I. Dodson, 1995. Synergistic, effects of low oxygen concentration, predator kairomone, and a pesticide on the cladoceran Daphnia pulex. Limnol. Oceanogr. 40: 700-709.
Hansson, L. A., 1996. Behavioural response in plants: adjustment in algal recruitment induced by herbivores. Proc. R. Soc. Lond. B 263: 1241-1244.

Hansson, L. A., 2000. Synergistic effects of food chain dynamics and induced behavioral responses in aquatic ecosystems. Ecology 81: 842-851.

Harvell, C. D., 1990. The ecology and evolution of inducible defences. Q. Rev. Biol. 65: 323-340.

Havel, J., 1987. Predator-induced defences: a review. In Kerfoot, W. C. \& A. Sih (eds), Predation: Direct and Indirect Impacts on Aquatic Communities. University Press of New England, Hanover, U.S.A.: 263-278.

Hebert, P. D. N., 1974a. Enzyme variability in natural populations of Daphnia magna. II. Genotypic frequencies in permanent populations. Genetics 77: 323-334.

Hebert, P. D. N., 1974b. Enzyme variability in natural populations of Daphnia magna. III. Genotypic frequencies in intermittent populations. Genetics 77: 335-341.

Hebert, P. D. N. \& P. M. Grewe, 1985. Chaoborus-induced shifts in the morphology of Daphnia ambigua. Limnol. Oceanogr. 30: 1291-1297.

Heller, R. \& M. Milinski, 1979. Optimal foraging of sticklebacks on swarming prey. Anim. Behav. 27: 1127-1141.

Hendry, A. C. \& C. W. Burns, 2001. Do potential predators induce an avoidance response in Daphnia carinata? NZ J. Mar. Freshwater Res. 35: 155-164.

Hessen, D. O. \& E. van Donk, 1993. Morphological changes in Scenedesmus induced by substances released from Daphnia. Arch. Hydrobiol. 127: 129-140.

Horppila, J., 1997. Diurnal changes in the vertical distribution of cladocerans in a biomanipulated lake. Hydrobiologia 345: 215220.

Jacobs, J., 1967. Untersuchungen zur Funktion und Evolution der Zyklomorphose bei Daphnia, mit besonderer Berücksichtigung der Selektion durch Fische. Arch. Hydrobiol. 62: 467-541.

Jensen, K. H., P. J. Jakobsen \& O. T. Kleiven, 1998. Fish kairomone regulation of internal swarm structure in Daphnia pulex (Cladocera: Crustacea). Hydrobiologia 368: 123-127.

Kamra, K. \& G. R. Sapra, 1994. Quantitative regulation of ciliary structures in polymorphic states of the hypotrichous ciliate Onychodromus indica. Euro. J. Protistol. 30: 379-393.

Kats, L. B. \& L. M. Dill, 1998. The scent of death: chemosensory assessment of predation risk by prey animals. Ecoscience 5: 361394.

Kerfoot, W. C. \& A. Sih eds, 1987. Predation: Direct and indirect impacts on aquatic communities. Hanover, U.S.A., University Press of New England.

Kleiven, O. T., P. Larsson \& A. Hobæk, 1996. Direct distributional response in Daphnia pulex to a predator kairomone. J. Plankton Res. 18: 1341-1348.

Krueger, D. A. \& S. I. Dodson, 1981. Embryological induction and predation ecology in Daphnia pulex. Limnol. Oceanogr. 26: 219223.

Kuhlmann, H.-W., 1992. Benefits and costs of predator-induced defences in Euplotes. J. Protozool. 39: 49A.

Kuhlmann, H.-W., 1994. Escape response of Euplotes octocarinatus to turbellarian predators. Arch. Protistenkd. 144: 163-171.

Kuhlmann, H.-W. \& K. Heckmann, 1985. Interspecific morphogens regulating prey-predator relationships in protozoa. Science 227 : 1347-1349.

Kuhlmann, H.-W. \& K. Heckmann, 1994. Predation risk of typical ovoid and 'winged' morphs of Euplotes (Protozoa, Ciliophora). Hydrobiologia 284: 219-227. 
Kusch, J., 1993a. Behavioural and morphological changes in ciliates induced by the predator Amoeba proteus. Oecologia 96: 354359.

Kusch, J., 1993b. Induction of defensive morphological changes in ciliates. Oecologia 94: 571-575.

Kusch, J., 1993c. Predator-induced changes in Euplotes (Ciliata); Isolation of the inducing substance released from Stenostomum sphagnetorum (Turbellaria). J. Exp. Zool. 841: 613-618.

Kusch, J., 1995. Adaptation of inducible defense in Euplotes daidaleos (Ciliophora) to predation risks by various predators. Microb. Ecol. 30: 79-88.

Kusch, J., 1998. Long-term effects of inducible defense. Ecoscience 5: $1-7$.

Kusch, J., 1999. Self-recognition as the original function of an amoeban defense-inducing kairomone. Ecology 80: 715-720.

Kusch, J. \& K. Heckmann, 1992. Isolation of the Lembadion-factor, a morphogenetically active signal, that induces Euplotes cells to change from their ovoid form into a larger lateral winged morph. Dev. Genet. 13: 241-246.

Kusch, J. \& H.-W. Kuhlmann, 1994. Cost of Stenostomum-induced morphological defence in the ciliate Euplotes octocarinatus. Arch. Hydrobiol. 130: 257-267.

Kvam, O. V. \& O. T. Kleiven, 1995. Diel horizontal migration and swarm formation in Daphnia in response to Chaoborus. Hydrobiologia 307: 177-184.

Lampert, W., 1987. Vertical migration of freshwater zooplankton: indirect effects of vertebrate predators on algal communities. In Kerfoot, W. C. \& A. Sih (eds), Predation: Direct and Indirect Impacts on Aquatic Communities. University Press of New England, Hanover, U.S.A.: 291-299.

Lampert, W., 1993. Ultimate causes of diel vertical migration of zooplankton: new evidence for the predator avoidance hypothesis. Arch. Hydrobiol. Beih. Ergebn. Limnol. 39: 79-88.

Lampert, W., K. O. Rothhaupt \& E. von Elert, 1994. Chemical induction of colony formation in a green alga (Scenedesmus acutus) by grazers (Daphnia). Limnol. Oceanogr. 39: 1543-1550.

Larsson, P. \& S. I. Dodson, 1993. Chemical communication in planktonic animals. Arch. Hydrobiol. 129: 129-155.

Lass, S., M. Boersma, K. H. Wiltshire, P. Spaak \& H. Boriss, 2001. Does trimethylamine induce life-history reactions in Daphnia? Hydrobiologia 442: 199-206.

Lauridsen, T. L., E. Jeppesen, S. F. Mitchell, D. M. Lodge \& R. L. Burks, 1999. Diel variation in horizontal distribution of Daphnia and Ceriodaphnia in oligotrophic and mesotrophic lakes with contrasting fish densities. Hydrobiologia 409: 241-250.

Lauridsen, T. L., E. Jeppesen, M. Sondergaard \& D. M. Lodge, 1998. Horizontal Migration of Zooplankton: Predator-mediated Use of Macrophyte Habitat, Structuring Role of Submerged Macrophytes in Lakes. Springer Verlag, Berlin, Germany 13: 233-239.

Lauridsen, T. L. \& D. M. Lodge, 1996. Avoidance by Daphnia magna of fish and macrophytes: chemical cues and predator mediated use of macrophyte habitat. Limnol. Oceanogr. 41: 794-798.

Lauridsen, T. L., L. J. Pedersen, E. Jeppesen \& M. Sondergaard, 1996. The importance of macrophyte bed size for cladoceran composition and horizontal migration in a shallow lake. J. Plankton Res. 18: 2283-2294.

Loose, C. J., 1993. Daphnia diel vertical migration behavior: response to vertebrate predator abundance. Arch. Hydrobiol. Beih. Ergebn. Limnol. 39: 29-36.

Loose, C. J. \& P. Dawidowicz, 1994. Trade-offs in diel vertical migration by zooplankton: the costs of predator avoidance. Ecology 75: 2255-2263.
Loose, C. J., E. von Elert \& P. Dawidowicz, 1993. Chemicallyinduced diel vertical migration in Daphnia - a new bioassay for kairomones exuded by fish. Arch. Hydrobiol. 126: 329-337.

Lüning, J., 1992. Phenotypic plasticity of Daphnia pulex in the presence of invertebrate predators - morphological and life history responses. Oecologia 92: 383-390.

Lüning, J., 1994. Anti-predator defenses in Daphnia - are lifehistory changes always linked to induced neck spines. Oikos 69: $427-436$.

Lüning, J., 1995a. How do predator-induced changes affect prey vulnerability? Larvae of Chaoborus flavicans (Diptera: Chaoboridae) feeding on Daphnia pulex (Crustacea: Cladocera). Freshwat. Biol. 34: 523-530.

Lüning, J., 1995b. Life-history responses to Chaoborus of spined and unspined Daphnia pulex. J. Plankton Res. 17: 71-84.

Lürling, M., 1998. Effect of grazing-associated infochemicals on growth and morphological, development in Scenedesmus acutus (chlorophyceae). J. Phycol. 34: 578-586.

Lürling, M., 1999a. Grazer-induced coenobial formation in clonal cultures of Scenendesmus obliquus (Chlorococcales, Chlorophyceae). J. Phycol. 35: 19-23.

Lürling, M., 1999b. The smell of water - Grazer-induced colony formation in Scenedesmus. Ph.D. Thesis, Agricultural University Wageningen, Wageningen, The Netherlands: $270 \mathrm{pp}$.

Lürling, M. \& W. Beekman, 1999. Grazer-induced defenses in Scenedesmus (Chlorococcales; Chlorophyceae): coenobium and spine formation. Phycologia 38: 368-376.

Lürling, M. \& E. van Donk, 1997. Morphological changes in Scenedesmus induced by infochemicals released in situ from zooplankton grazers. Limnol. Oceanogr. 42: 783-788.

Lürling, M. \& E. van Donk, 2000. Grazer-induced colony formation in Scenedesmus: are there costs to being colonial? Oikos 88: 111118.

Lynch, M., 1980. The evolution of cladoceran life histories. Q. Rev. Biol. 55: 23-42.

Lysebo, E. M., 1995. Behavioural and morphological changes in polymorphic Daphnia related to different predation regimes. Hydrobiologia 307: 185-191.

Macháček, J., 1991. Indirect effect of planktivorous fish on the growth and reproduction of Daphnia galeata. Hydrobiologia 225: 193-197.

Macháček, J., 1993. Comparison of the response of Daphnia galeata and Daphnia obtusa to fish-produced chemical substance. Limnol. Oceanogr. 38: 1544-1550.

Macháček, J., 1995. Inducibility of life history changes by fish kairomone in various developmental stages of Daphnia. J. Plankton Res. 17: 1513-1520.

Marinone, M. C. \& H. E. Zaragese, 1991. A field and laboratory study on factors affecting polymorphism in the rotifer Keratella tropica. Oecologia 86: 372-377.

Matsuda, H., M. Hori \& P. A. Abrams, 1994. Effects of predatorspecific defence on community complexity. Evol. Ecol. 8: 628638.

McKelvey, L. M. \& R. B. Forward Jr, 1995. Activation of brine shrimp nauplii photoresponses involved in diel vertical migration by chemical cues from visual and non-visual planktivores. J. Plankton Res. 17: 2191-2206.

Michels, E., M. Leynen, C. Cousyn, L. de Meester \& F. Ollevier, 1999. Phototactic behavior of Daphnia as a tool in the continuous monitoring of water quality: experiments with a positively phototactic Daphnia magna clone. Water Res. 33: 401-408.

Michels, E., S. Semsari, C. Bin \& L. de Meester, 2000. Effect of sublethal doses of cadmium on the phototactic behavior of Daphnia magna. Ecotox. Env. Saf. 47: 261-265. 
Mikulski, A., 2001. The presence of fish induces the quick release of offspring by Daphnia. Hydrobiologia 442: 195-198.

Neill, W. E., 1990. Induced vertical migration in copepods as a defence against invertebrate predation. Nature 345: 524-525.

Nordlund, D. A. \& W. J. Lewis, 1976. Terminology of chemical releasing stimuli in intraspecific and interspecific interactions. J. Chem. Ecol. 2: 211-220.

O’Bryan, L. M. \& G. E. Forrester, 1997. Effects of fish presence and simulated moonlight gradients on night time horizontal movements of a predatory zooplankter, Chaoborus punctipennis. J. Plankton Res. 19: 1441-1453.

Ohman, M. D., B. W. Frost \& E. B. Cohen, 1983. Reverse diel vertical migration: an escape from invertebrate predators. Science 220: 1404-1407.

Parejko, K. \& S. I. Dodson, 1991. The evolutionary ecology of an antipredator reaction norm - Daphnia pulex and Chaoborus americanus. Evolution 45: 1665-1674.

Peters-Regehr, T., J. Kusch \& K. Heckmann, 1997. Primary structure and origin of a predator released protein that induces defensive morphological changes in Euplotes. Euro. J. Protistol. 33: 389-395.

Petranka, J. W., 1989. Response of toad tadpoles to conflicting chemical stimuli: predator avoidance versus 'optimal' foraging. Herpetologica 45: 283-292.

Pijanowska, J., 1994. Fish-enhanced patchiness in Daphnia distribution. Verh. Internat. Verein. Limnol. 25: 2366-2368.

Pijanowska, J., 1997. Alarm signals in Daphnia. Oecologia 112: 12-16.

Pijanowska, J. \& A. Kowalczewski, 1997a. Cues from injured Daphnia and from cyclopoids feeding on Daphnia can modify life histories of conspecifics. Hydrobiologia 350: 99-103.

Pijanowska, J. \& A. Kowalczewski, 1997b. Predators can induce swarming behaviour and locomotory responses in Daphnia. Freshwat. Biol. 37: 649-656.

Pijanowska, J. \& G. Stolpe, 1996. Summer diapause in Daphnia as a reaction to the presence of fish. J. Plankton Res. 18: 1407-1412.

Pohnert, G. \& E. von Elert, 2000. No ecological relevance of trimethylamine in fish-Daphnia interactions. Limnol. Oceanogr. 45: 1153-1156.

Preston, B. L., G. Cecchine \& T. W. Snell, 1999a. Effects of pentachlorophenol on predator avoidance behavior of the rotifer Brachionus calyciflorus. Aquat. Toxicol. 44: 201-212.

Preston, B. L., T. W. Snell \& D. Dusenbery, 1999b. The effects of sublethal pentachlorophenol exposure on predation risk in freshwater rotifer species. Aquat. Toxicol. 47: 93-105.

Reede, T., 1995. Life history shifts in response to different levels of fish kairomones in Daphnia. J. Plankton Res. 17: 1661-1667.

Reede, T., 1997a. Effects of neonate size and food concentration on the life history responses of a clone of the hybrid Daphnia hyalina $\times$ galeata to fish kairomones. Freshwat. Biol. 37: 389396.

Reede, T., 1997b. Preliminary experiments on resource competition between a migrating and a non-migrating clone of the hybrid $D$. galeata $\times$ hyalina. Hydrobiologia 360: 109-115.

Reede, T. \& J. Ringelberg, 1995. The influence of a fish exudate on two clones of the hybrid Daphnia galeata $\times$ hyalina Hydrobiologia 307: 207-212.

Reede, T. \& J. Ringelberg, 1998. Differential life history responses of several pelagic Daphnia clones differing in migratory behaviour. Aquat. Ecol. 32: 245-253.

Rengefors, K., I. Karlsson \& L. A. Hansson, 1998. Algal cyst dormancy: a temporal escape from herbivory. Proc. R. Soc. Lond. B 265: 1353-1358.
Repka, S., M. Ketola \& M. Walls, 1994. Specificity of predatorinduced neck spine and alteration in life history traits in Daphnia pulex. Hydrobiologia 294: 129-140.

Repka, S. \& K. Pihlajamaa, 1996. Predator-induced phenotypic plasticity in Daphnia pulex: uncoupling morphological defenses and life history shifts. Hydrobiologia 339: 67-71.

Repka, S., M. Walls \& M. Ketola, 1995. Neck spine protects Daphnia pulex from predation by Chaoborus, but individuals with longer tail spine are at a greater risk. J. Plankton Res. 17: 393-403.

Ringelberg, J., 1987. Light induced behaviour in Daphnia. In Peters, R. H. \& R. De Bernardi (eds), 'Daphnia'. Pallanza, Italy, Mem. Inst. Ital. Idrobiol 45: 285-323.

Ringelberg, J., 1991. Enhancement of the phototactic reaction in Daphnia-hyalina by a chemical mediated by juvenile perch (Perca-fluviatilis). J. Plankton Res. 13: 17-25.

Ringelberg, J., 1993. Phototaxis as a behavioural component of diel vertical migration in a pelagic Daphnia. Arch. Hydrobiol. Beih. Ergebn. Limnol. 39: 45-55.

Ringelberg, J., 1997. Some suggestions for future cladoceran research. Hydrobiologia 360: 291-294.

Ringelberg, J., 1999. The photobehaviour of Daphnia spp. as a model to explain diel vertical migration in zooplankton. Biol. Rev. Cambridge. Phil. Soc. 74: 397-423.

Ringelberg, J. \& B. J. G. Flik, 1994. Increased phototaxis in the field leads to enhanced diel vertical migration. Limnol. Oceanogr. 39: 1855-1864.

Ringelberg, J., B. J. G. Flik, D. Aanen \& E. van Gool, 1997. Amplitude of diel vertical migration (DVM) is a function of fish biomass, a hypothesis. Arch. Hydrobiol. Beih. Ergebn. Limnol. 49: 71-78.

Ringelberg, J., B. J. G. Flik, D. Lindenaar \& K. Royackers, 1991a. Diel vertical migration of Daphnia hyalina (sensu latiori) in Lake Maarsseveen: Part 2. Aspects of population dynamics. Arch. Hydrobiol. 122: 385-401.

Ringelberg, J., B. L. G. Flik, D. Lindenaar \& K. Royackers, 1991b. Diel vertical migration of Daphnia hyalina (sensu latiori) in Lake Maarsseveen: Part: 1. Aspects of seasonal and daily timing. Arch. Hydrobiol. 121: 129-145.

Ringelberg, J. \& E. van Gool, 1995. Migrating Daphnia have a memory for fish kairomones. Mar. Freshwat. Behav. Physiol. 26: 249-257.

Ringelberg, J. \& E. van Gool, 1998. Do bacteria, not fish, produce 'fish kairomone'? J. Plankton Res. 20: 1847-1852.

Sakwińska, O., 2000. Trimethylamine does not trigger antipredatory life history shifts in Daphnia. Limnol. Oceanogr. 45: 988-990.

Scheiner, S. M. \& D. Berrigan, 1998. The genetics of phenotypic plasticity. VIII. The cost of plasticity in Daphnia pulex. Evolution 52: 368-378.

Sih, A., G. Enlund \& D. Wooster, 1998. Emergent impacts of multiple predators on prey. Trends Ecol. Evol. 13: 350-355.

Ślusarczyk, M., 1995. Predator-induced diapause in Daphnia. Ecology 76: 1008-1013.

Ślusarczyk, M., 1999. Predator-induced diapause in Daphnia magna may require two chemical cues. Oecologia 119: 159-165.

Ślusarczyk, M., 2001. Food threshold for diapause in Daphnia under the threat of fish predation. Ecology 82: 1089-1096.

Snell, T. W., 1998. Chemical ecology of rotifers. Hydrobiologia 387/388: 267-276.

Spaak, P., 1996. Temporal changes in the genetic structure of the Daphnia species complex in Tjeukemeer, with evidence for backcrossing. Heredity 76: 539-548. 
Spaak, P. \& M. Boersma, 1997. Tail spine length in the Daphnia galeata complex: costs and benefits of induction by fish. Aquat. Ecol. 31: 89-98.

Spaak, P. \& M. Boersma, 2001. The influence of fish kairomones on the induction and vertical distribution of sexual individuals of the Daphnia galeata species complex. Hydrobiologia 442: 185-193.

Spitze, K., 1992. Predator-mediated plasticity of prey life history and morphology: Chaoborus americanus predation on Daphnia pulex. Am. Nat. 139: 229-247.

Stemberger, R. S., 1988. Reproductive costs and hydrdynamic benefits of chemically induced defenses in Keratella testudo. Limnol. Oceanogr. 33: 593-606.

Stemberger, R. S. \& J. J. Gilbert, 1984. Spine development in the rotifer Keratella cochlearis: induction by cyclopoid copepods and Asplanchna. Freshwat. Biol. 14: 639-647.

Stibor, H., 1992. Predator-induced life-history shifts in a freshwater cladoceran. Oecologia 92: 162-165.

Stibor, H., 1995. Chemische informationen in limnischen RäuberBeute Systemen: Der EffeKt von Räubersignalen auf den Lebenszyklus von Daphnia spp. (Crustacea, Cladocera). Dissertation Thesis. Christian Albrecht Universität, Kiel, Germany: $148 \mathrm{pp}$.

Stibor, H. \& W. Lampert, 2000. Components of additive variance in life-history traits of Daphnia hyalina: seasonal differences in the response to predator signals. Oikos 88: 129-138.

Stibor, H. \& J. Lüning, 1994. Predator-induced phenotypic variation in the pattern of growth and reproduction in Daphnia hyalina (Crustacea: Cladocera). Funct. Ecol. 8: 97-101.

Stibor, H. \& D. M. Navarra, 2000. Constraints on the plasticity of Daphnia magna influenced by fish-kairomones. Funct. Ecol. 14: 455-459.

Stich, H. B. \& W. Lampert, 1984. Growth and reproduction of migrating and non-migrating Daphnia species under stimulated food and temperature conditions of diurnal vertical migration. Oecologia 61: 192-196.

Stirling, G., 1995. Daphnia behaviour as a bioassay of fish presence or predation. Funct. Ecol. 9: 778-784.

Strand, S. W. \& W. M. Hamner, 1990. Schooling behavior of Antarctic krill (Euphausia superba) in laboratory aquaria: reactions to chemical and visual stimuli. Mar. Biol. 106: 355-360.

Swaffar, S. M. \& W. J. O’Brien, 1996. Spines of Daphnia lumholtzi create feeding difficulties for juvenile bluegill-sunfish (Lepomis macrochirus). J. Plankton Res. 18: 1055-1061.

Taleb, H., N. Lair, P. Reyes Marchant \& J. L. Jamet, 1993. Observations on vertical migrations of zooplankton at four different stations of a small, eutrophic, temperate zone lake, in relation to their predators. Arch. Hydrobiol. Beih. Ergebn. Limnol. 39: 199-216.

Tollrian, R., 1993. Neckteeth formation in Daphnia pulex as an example of continuous phenotypic plasticity - morphological effects of Chaoborus kairomone concentration and their quantification. J. Plankton Res. 15: 1309-1318.

Tollrian, R., 1994. Fish-kairomone induced morphological changes in Daphnia lumholtzi (Sars). Arch. Hydrobiol. 130: 69-75.

Tollrian, R., 1995a. Chaoborus crystallinus predation on Daphnia pulex: can induced morphological changes balance effects of body size on vulnerability? Oecologia 101: 151-155.

Tollrian, R., 1995b. Predator-induced morphological defenses: costs, life history shifts, and maternal effects in Daphnia pulex. Ecology 76: 1691-1705.

Tollrian, R. \& S. I. Dodson, 1999. Inducible defenses in cladocera: constraints, costs, and multipredator environments. In Harvell, C. D. \& R. Tollrian (eds), Ecology and Evolution of Inducible
Defenses. Princeton University Press, Princeton, U.S.A.: 177202.

Tollrian, R. \& C. D. Harvell, 1999. The Ecology and Evolution of Inducible Defenses. Princeton University Press, Princeton, U.S.A.: 383 pp.

Tollrian, R. \& E. von Elert, 1994. Enrichment and purification of Chaoborus kairomone from water - further steps toward its chemical characterization. Limnol. Oceanogr. 39: 788-796.

van Gool, E. \& J. Ringelberg, 1995. Swimming of Daphnia galeata $\times$ hyalina in response to changing light intensities: influence of food availability and predator kairomone. Mar. Freshwat. Behav. Physiol. 26: 259-265.

van Gool, E. \& J. Ringelberg, 1997. The effect of accelerations in light increase on the phototactic downward swimming of Daphnia and the relevance to diel vertical migration. J. Plankton Res. 19: 2041-2050.

van Gool, E. \& J. Ringelberg, 1998a. Light-induced migration behaviour of Daphnia modified by food and predator kairomones. Anim. Behav. 3: 741-747.

van Gool, E. \& J. Ringelberg, 1998b. Quantitative effects of fish kairomones and successive light stimuli on downward swimming responses of Daphnia. Aquat. Ecol. 32: 291-296.

van Gool, E. \& J. Ringelberg, 1999. Estimates of effective kairomone concentration in the field may predict diel vertical migration. Abstract ASLO Conference Feb. 1-5 Santa Fe: 183.

von Elert, E. \& A. Franck, 1999. Colony formation in Scenedesmus: grazer-mediated release and chemical features of the infochemical. J. Plankton Res. 21: 789-804.

von Elert, E. \& C. J. Loose, 1996. Predator-induced diel vertical migration in Daphnia - enrichment and preliminary chemical characterization of a kairomone exuded by fish. J. Chem. Ecol. 22: 885-895.

von Elert, E. \& G. Pohnert, 2000. Predator specificity of kairomones in diel vertical migration of Daphnia: a chemical approach. Oikos 88: 119-128.

Washburn, J. O., M. E. Gross, D. R. Mercer \& J. R. Anderson, 1988. Predator-induced trophic shift of a free-living ciliate: parasitism of mosquito larvae by their prey. Science 240: 1193-1195.

Watt, P. J. \& S. Young, 1992. Genetic control of predator avoidance behaviour in Daphnia. Freshwat. Biol. 28: 363-367.

Watt, P. J. \& S. Young, 1994. Effect of predator chemical cues on Daphnia behaviour in both horizontal and vertical planes. Anim. Behav. 48: 861-869.

Weber, A., 1999. The importance of infochemicals and clonespecific phenotypic plasticity in Daphnia ecology. $\mathrm{PhD}$ Thesis. University of Utrecht, Utrecht, The Netherlands: $165 \mathrm{pp}$.

Weber, A. \& S. Declerck, 1997. Phenotypic plasticity of Daphnia life history traits in response to predator kairomones: genetic variability and evolutionary potential. Hydrobiologia 360: 89-99.

Weider, L. J. \& J. Pijanowska, 1993. Plasticity of Daphnia life histories in response to chemical cues from predators. Oikos 67: 385-392.

Wicklow, B. J., 1997. Signal-induced defensive phenotypic changes in ciliated protists: morphological and ecological implications for predator and prey. J. Eukar. Microbiol. 44: 176-188.

Wiltshire, K. H. \& W. Lampert, 1999. Urea excretion by Daphnia: a colony-inducing factor in Scenedesmus? Limnol. Oceanogr. 44: 1894-1903.

Wolf, H. G., 1987. Interspecific hybridization between Daphnia hyalina, D. galeata and D. cucullata and seasonal abundance of these species and their hybrids. Hydrobiologia 145: 213-217.

Young, S. \& V. A. Taylor, 1990. Swimming tracks in swarms of two cladocera species. Anim. Behav. 39: 10-16. 
Young, S. \& P. Watt, 1993. Behavioral mechanisms controlling vertical migration in Daphnia. Limnol. Oceanogr. 38: 70-79.

Young, S. \& P. J. Watt, 1994. Behavioural and genetic differences in populations of Daphnia subjected to different levels of predation. Freshwat. Biol. 32: 479-487.
Zaret, T. M. \& J. S. Suffern, 1976. Vertical migration in zooplankton as a predator avoidance mechanism. Limnol. Oceanogr. 21: 804813. 